\title{
LAUNCH MINDS: LAUNCH YOUR CHILD'S FUTURE - A BUSINESS CASE
}

\author{
by \\ Ramage Zaki \\ Bachelor of Technology, Ryerson University, 2016
}

\author{
A major research project \\ presented to Ryerson University \\ in partial fulfillment of the \\ requirements for the degree of \\ Master of Digital Media \\ in the program of Digital Media
}

Toronto, Ontario, Canada, 2019

(C)Ramage Zaki, 2019 


\section{AUTHOR'S DECLARATION FOR ELECTRONIC SUBMISSION OF AN MRP}

I hereby declare that I am the sole author of this MRP. This is a true copy of the MRP, including any required final revisions.

I authorize Ryerson University to lend this MRP to other institutions or individuals for the purpose of scholarly research.

I further authorize Ryerson University to reproduce this MRP by photocopying or by other means, in total or in part, at the request of other institutions or individuals for the purpose of scholarly research.

I understand that my MRP may be made electronically available to the public. 


\title{
LAUNCH MINDS: LAUNCH YOUR CHILD'S FUTURE - A BUSINESS CASE
}

\author{
Ramage Zaki \\ Master of Digital Media \\ Digital Media \\ Ryerson University, 2019
}

\begin{abstract}
According to a 2018 Ipsos survey 7 in 10 parents (70\%) advocate the idea of having their children involved in extracurricular activities because of their perceived benefits (Simpson, 2018). However, many of them face the problem of spending countless hours researching available activities, leading to much wasted effort with no valuable results in return. The Launch Minds business case focuses on how a digital solution aimed at aggregating and filtering information, can allow parents to research, find, and register all their children within one platform. In turn, it discusses how this can lead to a cost-effective solution that encourages children to get involved in a diverse range of activities.
\end{abstract}




\section{Acknowledgments}

"Gratitude can transform common days into thanksgivings, turn routine jobs into joy, and change ordinary opportunities into blessings." - William Arthur Ward

First and foremost, to my parents who have done everything in their willpower and sacrificed a lot to get my brothers and I to where we are today. For believing in me every step of the way, for supporting my dreams, and always helping me be the best version of myself; I owe you everything - thank you. To my brother who stood by me, learnt how to code, and worked tirelessly to help me bring my idea to life, thank you for everything.

To my friends who have been a constant source of support as my very own personal cheerleaders, for helping me through the different obstacles I may have encountered, and for always being there front row and center, I can't thank you enough.

Most importantly, I would like to thank my academic supervisor, Ahmed Sagarwala, who guided me, believed in me, and supported me every step of the way from the time this was just an idea for an assignment to helping me launch my business and legally incorporate it. Thank you for spending hours on hours listening to me, brainstorming with me, and helping me overcome the different road bumps I've encountered along the way. I would also like to thank my secondreader, Professor Paul Moore, who pushed me to think outside the box and guided me on how 
to best approach this idea and the research behind it. Without you both, the Master of Digital media program, and my colleagues from the 6.0 cohort, I wouldn't be where I am today.

I can't thank everyone enough who has been a part of this achievement thus far! I look forward to not only spreading this knowledge and inspiring others but continuing to achieve more success with your support. 


\section{Table of Contents}

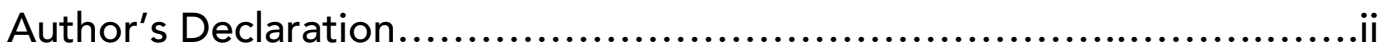

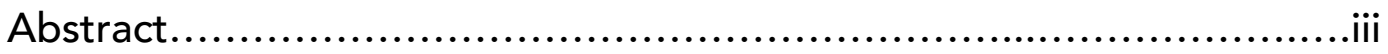

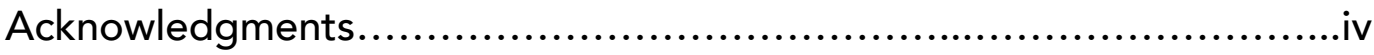

List of Tables....................................................................viii

List of Illustrations..................................................................

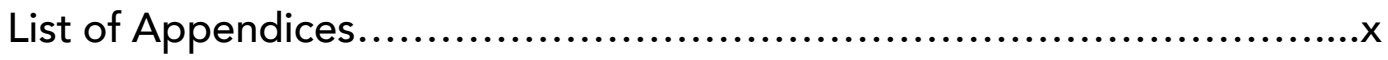

1. Introduction......................................................................1

$1.1 \quad$ Problem Statement.............................................

2. Background Research.........................................................3

2.1 Concept of STEAM in Education.................................

2.2 Extracurricular and Child Development.........................4

2.3 Importance of Sports in Extracurriculars............................5 
2.4 Market Research - Overview and Current Trends. 6

\section{Project Plan.....................................................................8}

3.1 Idea Validation................................................

3.2 User Persona................................................... 10

3.3 Business Plan..................................................11

3.4 App Development........................................... 15

3.5 Future Growth Opportunities.................................16

4. Outcomes..................................................................................19

4.1 Facilitated Research Process for Users..........................19

4.2 Access to Fun, Educational Workshops........................20

\section{Conclusion...............................................................21}

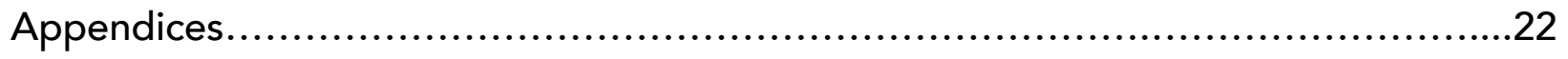

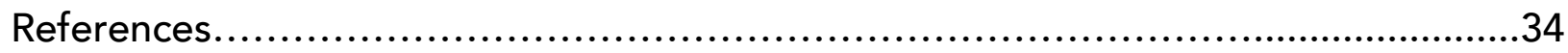




\section{List of Tables}

Table 3.1 - SWOT Analysis........................................................... 


\section{List of Illustrations}

Illustration 1.1 - Problems faced by parents when searching for extracurriculars............1

Illustration 2.1 - Benefits of children being involved in extracurriculars...................5

Illustration 3.1 - Launch Minds Business Model..........................................12

Illustration 3.2 - Activity categories offered on the Launch Minds platform................15 


\section{List of Appendices}

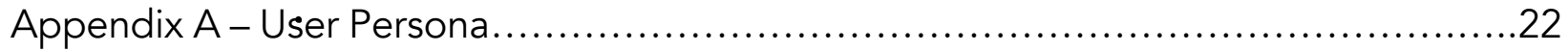

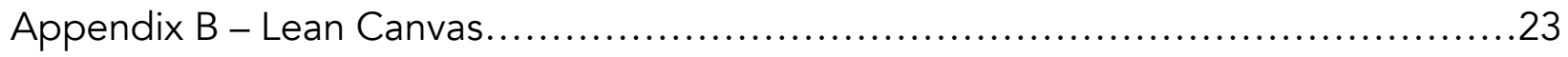

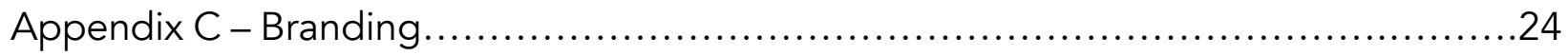

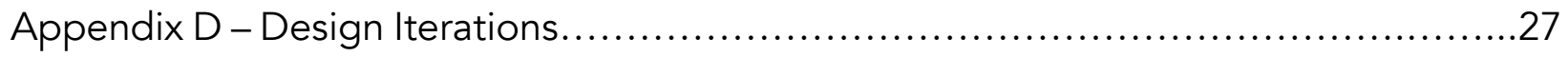




\section{Introduction}

Technology has infiltrated every aspect of our lives in the past few years, with many studies even warning parents of children developing screen dependency disorders when spending up to three hours a day starting at a device (Curtis, 2017). This dependency has in turn caused today's children to become less exposed to the outside world and its opportunities for extracurriculars with the purpose of fun and education. I have personally witnessed this with my youngest brother, being eleven years old and not wanting to leave the house at times due to his fear of becoming bored without his devices. Additionally, parents' inability to find what they are searching for the majority of the time is a major deterrent. Many parents face the frustration of spending countless hours and opening various tabs only to end up either not finding the right activity or feeling overwhelmed with the amount of information they have encountered.

\subsection{Problem Statement}

Problem 1

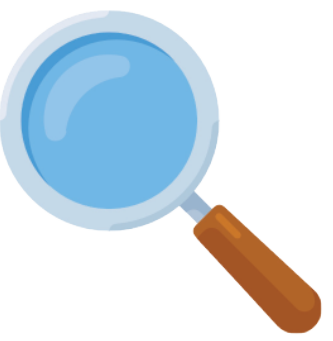

Finding

Information

Easily
Problem 2

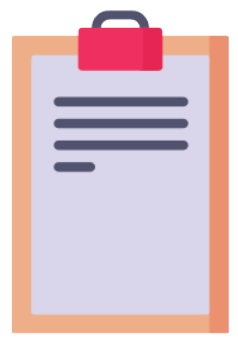

Registering

for

Activities
Problem 3

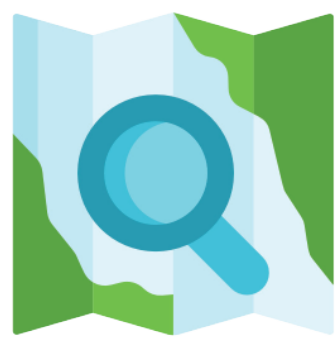

Finding

Activity Close

in Proximity

Illustration 1.1 - Problems faced by parents when searching for extracurriculars 
The paradox is that there exists a variety of extracurricular activities across a multitude of disciplines with both online and offline options. However, parents are constantly facing the frustration of not finding the right activity that meets their child's interests, not finding information easily, and at times not finding activities that are close in proximity. Therefore, it remains crucial to overcome these obstacles, educating children early on and helping them develop essential skills both intellectually and emotionally as they navigate the future that lies ahead of them. It is on that basis that I aim to develop a solution that consolidates all required information with regards to the available programs based on location, area of interest, and age group. 


\section{Background}

\subsection{Concept of STEAM in Education}

With the continual introduction of new teaching methods that focus on educators bringing new innovative methods to the classroom, STEAM is an emerging paradigm that is starting to be incorporated in many curriculums and extracurricular programs. This method is slowly proving to be successful as it is trans-disciplinary spanning across different fields while encouraging problem solving through real life scenarios; hence preparing students for the future workforce. "STEAM encourages the young learner to discover how to create new things; see familiar things in new ways; combine things in non-traditional ways; and to think independently and unconventionally" (Jamil, Linder, \& Stegelin, 2017). This method helps build children that are risk takers who can easily tackle daily problems in new, creative ways.

As this still remains a new concept that is slowly being introduced in classrooms, there is no specific teaching method that outlines how STEAM should be incorporated. It is suggested that the teacher's methodology and beliefs have a strong influence on its success (Jamil, Linder, \& Stegelin, 2017). Nevertheless, this gives educators the freedom to adapt different ways of implementing these methods based on the children's needs, offering them the flexibility to unleash their full potential. One of the primary reasons behind focusing the application on this approach is to ensure that children and youth have a chance to develop these skills early on and in turn become more competitive globally. 


\subsection{Extracurriculars and Child Development}

Extracurricular programs, also referred to as organized activities, help contribute to child development. These activities are not only characterized by their structure, but also by their emphasis on skill building. Through adult guidance, children are able to understand the ultimate goal and are able to develop particular skills both individually and as part of a team. After school activities, community building programs, workshops, and classes aid in the "healthy development of civically engaged, thriving youth" (Mahoney, Larson, \& Eccles, 2008). Additionally, these programs help build a sense of community and aid youth in building skills required to survive in the real world. According to several studies, being involved in a number of extracurriculars resulted in many positive outcomes including higher math test scores, increased prosocial behaviour, and lower probabilities of negative outcomes such as drinking at a young age or substance use (Guèvremont, Findlay \& Kohen, 2011).

All these skills gained from participating in workshops and classes both in and out of school, can be employed by children in many future scenarios they come across as they prepare to face the real-world on their own. According to a recent Capital One® survey, some parents have claimed that being involved in extracurriculars has helped their children become more independent, responsible, and learned to value money ("Back To School: Investing In Kids' Extracurricular Activities", 2018). This also ties in with the goal of STEAM to help students build the creative knowledge to deal with real-world problems. Moreover, in collaboration with the STEAM program introduced in schools, children are able to develop their skills further as it helps them build competencies that are not traditionally learned within a school setting. Based on 
extensive research it has also been established that "school activity participation is associated with a reduction in rates of early school dropout, particularly for high-risk youth" (Mahoney \& Cairns, 1997). This comes to prove the power of education and skill development in the shaping of the future generation.

Personally

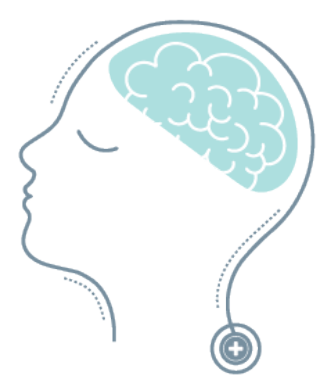

Socially

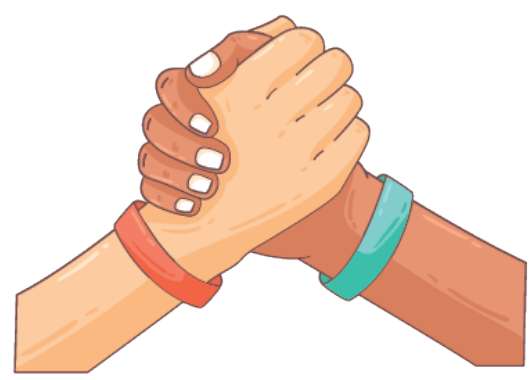

\section{Professionally}

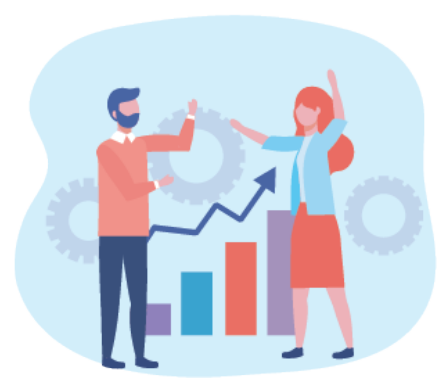

Illustration 2.1 - Benefits of children being involved in extracurriculars

\subsection{Importance of Sports in Extracurriculars}

Organized activities go beyond STEAM as well by incorporates sports. Commonly sports are known to improve physical health and reduce the risk of many medical conditions. Nevertheless, there is also research to support that sports contribute to one's mental and social health (Felfe, Lechner \& Steinmayr, 2016). As an organized activity, it links back to skill development as members of teams are taught to deal quickly with different scenarios they may encounter. Players must be quick to think on their feet and react to problems as they arise, both on their own and as part of their team. They need to develop the skills to support one another and be able to build on each other's strengths. Furthermore, research has confirmed that many 
parents have reported their children becoming more socially active and involved as they learn to develop their communication and teamwork skills as they make new friends and foster a positive relation with their coaches and teammates. Additional benefits include being "emotionally controlled, enjoying exploration, having confidence and discipline, performing well academically, managing their weight and being "kept busy'" (Eime, Young, Harvey, Charity, \& Payne, 2013).

\subsection{Market Research - Overview and Current Trends}

From a business standpoint, Launch Minds primarily operates within the education, childcare, and child enrichment industry; with a focus on extracurricular programs. According to a 2018 IPSOS survey, seven in ten parents (70\%) believe that it is important to have their children involved in extracurriculars; with some parents going as far as going into debt (Simpson 2018).

"Despite coughing up serious dough to keep their children active and engaged, the vast majority think the expense is worth it as nine in ten agree that it is important to give children as many diverse experiences as possible (91\%), and that the options available for children today are better than ever before (89\%)" (Simpson, 2018).

The survey also identified that on average parents spend around $\$ 1,160$ annually on extracurricular activities, an increase of $3.5 \%$ from the previous year. However, while many parents strain their family budget with one in three (32\%) families going into debt to fund their children's extracurriculars, many claim that they do not see this as an issue as they believe the benefits outweigh the costs (Simpson, 2018). Moreover, based on the 2018 IPSOS survey it was 
identified that children's interests are changing as well with an increased enrollment in music, dance, gymnastics, art, and language classes in comparison to preceding years (Simpson, 2018) ${ }^{1}$.

${ }^{1}$ Access 2018 Ipsos Survey "One in Three (32\%) Families Going into Debt to Fund their Children's Extra-Curricular Activities, Up 5 Points from Last Year" here: https://www.ipsos.com/en-ca/news-polls/back-to-school-2018 


\section{Project Plan}

With the previously mentioned benefits and the growing dependency on technology, it is important to develop a solution that is readily accessible while facilitating the search and registration process for extracurriculars. For this to be achieved the current problem parents face, with the difficulty of finding the right extracurriculars due to the time consuming and inefficient process of current solutions, must first be addressed. Adopting the design thinking approach will provide a solid foundation to solving the problem via a solution-based approach that understands the human needs involved and adopts a hands-on approach in prototyping and testing (Dam \& Siang, 2018).

\subsection{Idea Validation}

According to the design thinking approach, one must first start by validating the viability of the idea at hand or solution to be offered as well as define the problem (Dam \& Siang, 2018). Over the years there has been a growing number of child-centric programs across multiple disciplines. However, it takes parents hours to find compatible activities for their children from a trusted online source. By developing a mobile application that aggregates and filters information on the available programs based on location, area of interest, and age group, parents would have a one-stop shop to search, compare, and register for activities all on one platform. This solution is aimed to not only save them time, but also increase child participation as populations continue to grow.

In order to assess the viability of the idea, a SWOT analysis was conducted to understand current trends and the position of Launch Minds within the market. 
Table 3.1 - SWOT Analysis

\begin{tabular}{|c|c|}
\hline Strengths & Weaknesses \\
\hline $\begin{array}{l}\text { Access to large network of parents who are } \\
\text { willing to use the app and help promote it. } \\
\text { Leveraging resources available through } \\
\text { Ryerson University's Master of Digital Media } \\
\text { program. } \\
\text { App features including one-click registration, } \\
\text { geo mapping, and curated search results for } \\
\text { each child. }\end{array}$ & $\begin{array}{l}\text { Not an established company so building } \\
\text { program partnerships may be difficult at first. } \\
\text { High initial development costs. }\end{array}$ \\
\hline Opportunities & Threats \\
\hline $\begin{array}{l}\text { No app exists with a direct focus on the } \\
\text { Canadian market with a user-friendly interface } \\
\text { that streamlines the search and registration } \\
\text { process. } \\
\text { Over } 700,000 \text { families with children in Toronto } \\
\text { ("2016 Census: Families, households and } \\
\text { marital status; Language ", 2017). } \\
\text { Increasing number of parents looking to } \\
\text { involve their children in extracurriculars. }\end{array}$ & $\begin{array}{l}\text { US competitors who have the ability to } \\
\text { potentially expand to Canada. } \\
\text { Indirect competitors might also have the } \\
\text { ability to expand their offerings. } \\
\text { Community Centers owning a big share of the } \\
\text { extracurricular activity market }\end{array}$ \\
\hline
\end{tabular}




\subsection{User Persona²}

Based on the preceding research, it can be concluded that the user persona is that of a parent who can be referred to as Sandy Soccer-Mom. She is a mother in her late forties with 2 children, one boy and one girl. She is adamant about having her children involved in extracurricular activities to help them build and learn new skills, socialize with others and eventually prepare them for university. In addition, she is interested in having them partake in activities related to sports, technology and arts, and is concerned with pricing, scheduling and location during her search.

Nonetheless, while Sandy's children are currently enrolled in extracurriculars, she still faces several problems when trying to find the ideal activity for them. Sandy's main source of information is particularly through Google search or word-of-mouth from friends and family. Not only is this process difficult and time consuming, but she complains that at times there isn't enough information available, she can't find activities close to where she lives, or doesn't know how or where to begin searching for the information. Hence, Sandy Soccer-Mom is willing to adopt a user-friendly solution that facilitates her search for extracurriculars, allowing her to filter based on location, age, interest, etc., register and pay, along with a number of other features all with the click of a button on her device.

\footnotetext{
${ }^{2}$ Refer to Appendix A - User Persona for an infographic outlining the user persona journey
} 


\subsection{Business Plan ${ }^{3}$}

\section{Product}

Launch Minds is a native application that aims to connect parents with extracurriculars for their children. One of the main features offered by this app is the curation feature that aggregates, and filters information based on the child's profile, which includes age, interests, and possibly gender if the parent decides to identify it. The company is keen on incorporating diversity and inclusion in every step of the strategy, by featuring activities that cater to children with disabilities to create an equal opportunity for all. This is crucial to ensuring that no child feels excluded and all their needs are accounted for.

\section{Place}

The Launch Minds app will be a native mobile application that is downloadable through the Apple or Google Play stores. This ensures that both iPhone and Android users have access to the app to ensure a wide array of users. It should be noted that to reduce costs while usertesting, the app will initially be available on the Apple App Store as there is a larger number of iPhone users within the target market. Moreover, the reason behind designing a mobile native app in contrast to a web app is to develop a seamless user experience. However, as the business grows the company will scale to include a desktop web version providing users with an additional access point.

\footnotetext{
${ }^{3}$ Refer to Appendix B - Lean Canvas to gain further understanding of the business strategy
} 


\section{Price}

The company business model is based on partnering up with different organizations to feature their activities on the platform. The company would then take a percent commission out of every activity registered. On that basis, the prices set on the app must be adjusted in accordance with the current cost of the programs set by the host organizations.
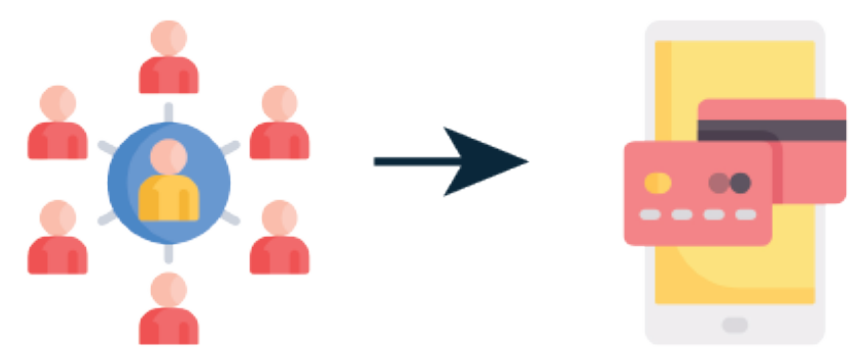

Partner with different

organizations, featuring

their activities on the database

$$
\text { the programs set by the host organizations. }
$$

Illustration 3.1 - Launch Minds Business Model

\section{Promotion $^{4}$}

Launch Minds will operate in a double-sided market, meaning it will target both organizations whose activities are to be featured on the platform, as well as the end users - the parents who are in search of activities for their children.

\footnotetext{
${ }^{4}$ Refer to Appendix C - Branding for more insight on the brand design concept that is a crucial aspect of promotion
} 
From a client perspective, the success of this application is based on partnerships with organizations that offer activities that fall within the targeted disciplines and target an age range of 3-17. By conducting a thorough market search, organizations that meet the required criteria will be contacted initially by phone to introduce them to Launch Minds and start building a relationship. A follow-up email would be the next step to reiterate the details of the call, leading clients to the website where they can learn more about the company and confirm an in person meeting. Consequently, the meeting will involve walking the client through a demo while pitching the company offerings. On that basis a partnership agreement would start to be built between Launch Minds and the host organization. Of course, it should be noted that online promotional strategies will also be targeted at organizations to entice them to be part of the Launch Minds community. To create a valuable experience for clients, the sales team would be comprised of account executives who are responsible for building and maintaining client partnerships. In addition, Launch Minds will also hire a customer success team to work alongside the account executives to ensure client problems are addressed. They would also be responsible for finding opportunities to improve on the product and scale the business.

From a user perspective, both online and offline promotional strategies will be utilized. The first step to promoting Launch Minds and building an online presence is developing a website that would act as a minimal viable product (MVP) to test product/market fit. It would serve as a platform to relay information about the business and its offerings to both mobile app users and organizations that the company aims to partner with. The website would also point users to a download link for the app while acting as a communication medium. Another important role is for search engine optimization (SEO) purposes, aimed at increasing traffic. The website 
URL is also important. The domain www.launchminds.ca incorporates the business name, which uses relevant keywords for the industry being served. The .ca website ending is an internet country code top-level domain that enhances SEO, increasing the searchability of the website within the Canadian market. Apart from the website, it is important to build an online social network presence to not only promote the company, but also build a community of users which is a crucial strategy in today's market. Nowadays consumers search for experiences rather than another product or service (Kumar, 2018). Launch Minds aims to build its community by providing consumers with information about the company and featured activities, as well as resources that can prove helpful to parents.

There has been a recent shift in marketing trends from traditional efforts to experiencebased marketing. Building relationships has become a primary goal, with profits being second on the list. Research shows that experiential marketing has resulted in higher user engagement and "lasting connections with consumers" (Olenski, 2018). On that premise, Launch Minds will aim to host pop-up events in partnership with different organizations to cater to parents who may be searching for one-day activities. Having real families and social influencers register for this event would be a great boost to the marketing strategy. Hosting these types of events, will help build a personal connection with the Launch Minds community of users as well as encourage more users to join as they realize the platform's value. Apart from these events, the company will ideally participate in both networking events and conferences pertaining to children, extracurriculars, or ideally both. This involvement is aimed at building partnerships with potential organizations, all while increasing outreach and building the community of users. 


\subsection{App Development ${ }^{5}$}

The third stage in the design thinking approach is the ideation process. Once the idea has been flushed out and validated, application design commences. The application will focus on connecting parents to workshops and classes that match their child's interest(s). To facilitate this outcome, activities will be categorized based on the different fields in which they are offered. To enhance adolescent development, the programs must cover the fields of science, technology, arts, music, and math, in addition to sports (Guèvremont, Findlay \& Kohen, 2011). These areas of interest are both educational and help develop the children's skills, as even youth using the application have the opportunity to attend classes that can later help them decide which career path they would like to pursue before transitioning to college or university. This approach will facilitate the search process for parents and youth, which is a primary objective of the application.
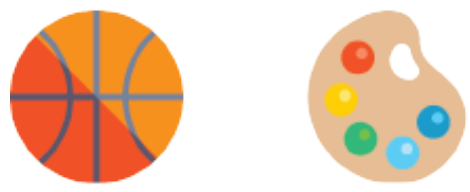

Arts

Sports

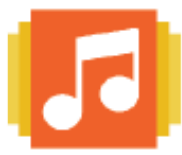

Music

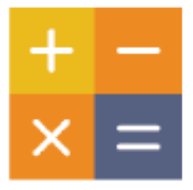

Math
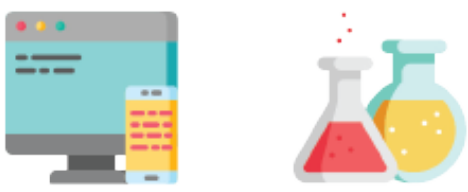

Illustration 3.2 - Activity categories offered on the Launch Minds platform

Another important aspect of the application is the incorporation of search filters to enhance the search process. It is crucial to understand the different criteria users may require to facilitate their search. For example, one common search function is a geo-filter. Categorizing

\footnotetext{
${ }^{5}$ Refer to Appendix D - Design Iterations for a preview of the different design concepts the app prototype underwent
} 
activities based on location and proximity allows users to view workshops and classes offered within their vicinity. Scheduling is another vital criterion that many parents and adolescents consider when registering for an activity, as they must ensure that they coordinate the different activities and that it fits around their school schedule. Research shows high levels of participation do not appear to hinder child performance. On the contrary, it helps enhance their development and results in more positive outcomes (Guèvremont, Findlay \& Kohen, 2011). It is important to still be able to find the right balance to avoid children feeling overwhelmed due to the number of activities and work obligations. Other important factors include age, budget to cater to families of different income levels, and type of activity (individual or team based), among many others yet to be discovered through beta testing and user feedback.

To handle user payments using a secure method, Launch Minds will utilize the Stripe API allowing the company to accept credit cards directly through the app. Although using an established external payment processor will result in a processing fee cost being incurred by Launch Minds, it is an important step to add value and ensure parents feel safe using the platform to register their children. In addition, this helps relieve the company of possible legal and developmental issues accompanied with the collection of personal information.

\subsection{Future Growth Opportunities}

It is important to ensure that as the business continues to grow, new value offerings are added to the business model, such as expanding the range of activities offered. These offerings will consequently help retain existing users and clients, attract new potentials. While constant 
user testing and feedback is important to discover new opportunities that meet the consumers' needs, below are a few examples of prospects to be explored.

\section{Creating a Loyal Community of Users}

One way of encouraging repeat purchases are loyalty programs. Based on the pricing strategy, it would be more effective to apply this system to seasonal and monthly programs that have a higher price tag. Users would be able to collect loyalty reward points that they can then redeem for discounts towards future purchases. In addition, Launch Minds can partner with vendors, such as Sport Chek, allowing users to redeem their points in return for discounts at merchandise stores, restaurants, and shopping outlets. These systems would be implemented to nurture children and increase their self-esteem and confidence, and encourage repeat performance ("Praise, encouragement and rewards", 2018).

Eventually, the platform could provide advice to parents via blog posts on industry trends, relevant research, child related articles, and event postings, among many others. This would help establish the application as a credible source for parents and youth.

\section{Building Additional Features}

Seasonal programs have a fixed schedule that registrants must abide by on a weekly basis. At times there may be unforeseen circumstances that come up and parents struggle to get their children to the scheduled activity. By creating a community of users, an in-app messaging platform can be built to connect users who are registered for the same program. Users can communicate via this platform to coordinate carpools, inform one another of relevant updates, and coordinate meetup times outside of scheduled activity times, and much more. 


\section{Expanding the Target Market}

While children aged three to seventeen are at the prime age for development, there are countless other users that lie outside of this age group that struggle to find programs to participate in. Once the primary target market has been well-established, the app can expand its offerings to cater to different age groups. Seniors are an example of a relevant target market that struggle to find programs that suit their interests, fill their spare time, and even help them gain new skills. Moreover, while many millennials experience difficulty finding programs that help them expand their network and their skills without breaking the bank.

\section{Child Performance Feedback}

An important aspect parents search for when involving their children in extracurriculars is feedback on their child's progress. Parents want to know that their children are getting their money's worth and are benefiting from the activities they are involved in. While progress can be visible as children level up, advancement often takes time and parents look for that feedback towards an outcome. On that basis, by paying a small premium, parents could gain access to monthly data on their child's performance. In order to facilitate this process for the instructors and avoid it taking up their time, back-end access would be comprised of pre-set form that they can easily complete. 


\section{Outcomes}

To define the true success of this project it is important to define measurable and attainable goals that set foundational grounds to build a viable business idea on. As this application focuses on connecting users with workshops, classes, and extracurricular programs within their area of interest it is important that the main goal be facilitating the research process.

\subsection{Facilitated Research Process for Users}

The process of finding workshops has often become very tiresome with numerous options exiting in the market. Parents spend countless hours surfing the internet opening various tabs only to find themselves spending hours online simply to be overwhelmed with a wide range of information that becomes difficult to filter through and in turn make a decision. Some parents have difficulty knowing what to search for in the first place. Others rely on online groups and word-of-mouth to inform them of what may be available in the market but with no actual way to determine if it is the ideal activity for their child. By partnering up and reaching out to organizations, community centers, and certified instructors that offer different programs to the defined target market of adolescents; the application will aim to provide users with a consolidated list of available classes and activities that are easy to navigate and filter through. By facilitating the research process and providing a way for parents to register directly through the app with the click of a button, users will be more encouraged to utilize the application and encourage their children to become more involved and engaged in their community as opposed to being glued to their device screens. 


\subsection{Access to Fun, Educational Workshops}

Another important outcome behind this project is child development. Involvement in extracurricular activities has proven to be a strong factor in the development of children on a personal and professional level. Not only are there several health benefits associated with many different activities including sports, music, and arts just to name a few, but there are several positive outcomes that result from children participating in such programs. These outcomes include increased social skills, reduced negative attributions such as alcohol and drug abuse, and improved school performance (Guèvremont, Findlay \& Kohen, 2011). Furthermore, partaking in such programs allows children and youth to learn several hard and soft skills that would help them navigate the real-world as they learn to problem solve early on. Whether it be team working skills learnt through sports or computer programming skills learnt from a specialized course, it all leads to children becoming more educated and helping them to think more creatively and strategically when faced with real-life problems. Through the implementation of programs across diverse range of interests based on the concept of STEAM, along with sports, children will have access to many programs that are aimed at having both having fun and developing their skills. 


\section{Conclusion}

In summary, by integrating STEAM with extracurricular programs, members of the community will have access to equal education opportunities that will help in shaping the leaders of tomorrow. All these programs and activities have proven to be indispensable in child development. Research has shown that children involved in such programs possessed higher social skills and skill development in comparison to those who did not (Eime, Young, Harvey, Charity, \& Payne, 2013). Over the years, there has been a rise in the number of companies developing workshops and classes that can be easily accessible to children via online or physical platforms. Consequently, the development of this application is to help bring forth these organized activities to increase outreach and engagement in hope of fostering a more well-rounded generation that is ready to face the future and lead us to the next big thing. 


\section{Appendices}

\section{Appendix A - User Persona}

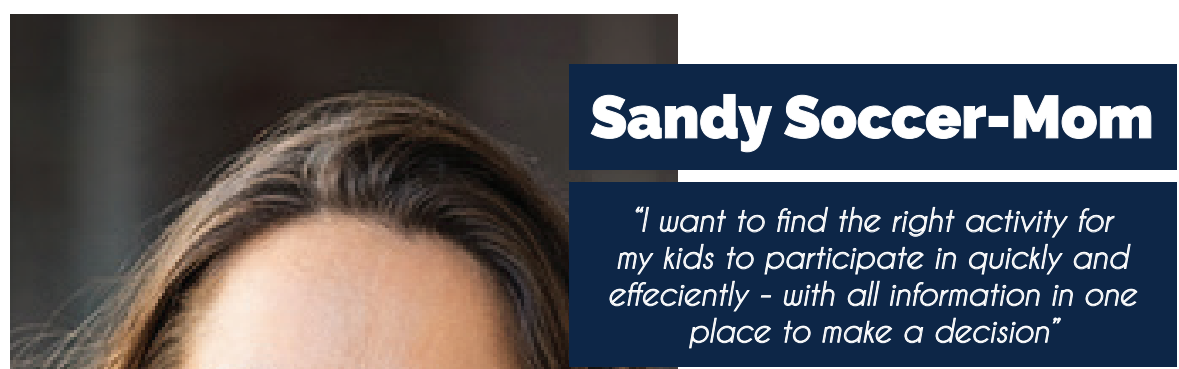

Age: 48

Job Status: Full-Time Employee

Average Income: 50K

Number of Children: 2

Age of Children: $7-12$ \& $13-17$

Location: North York, TO

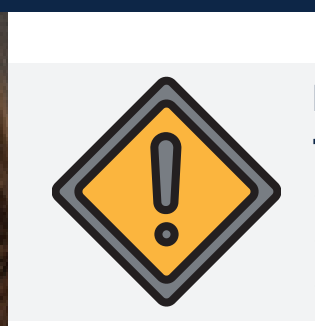

\section{Frustrations Faced During Search for Activities}

Not enough information available

Can't find activities close to where she lives

Difficult to register for acitvity at times

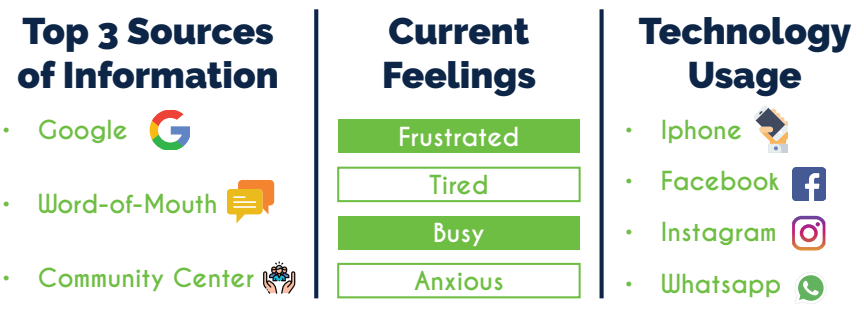

\section{Goals}

Find activity that meets children's interests

Find activity that is close in proximity

Find activity that meets her family's schedule

Find activity within her budget

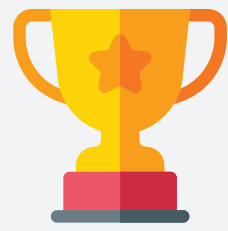

Motivations behind enrolling her children in activities

Learn and develop new skills

Socialize with others

Prepare them for University

Build healthy habits 


\section{Appendix B - Lean Canvas}

\section{Launch - Launch Canvas}

\begin{tabular}{|c|c|c|c|c|}
\hline $\begin{array}{l}\text { PROBLEM } \\
\text { \#Problem1 - Parents find } \\
\text { it difficult to find } \\
\text { information in the first } \\
\text { place on available activities } \\
\text { \#Problem2 - Parents have } \\
\text { difficulty registering for } \\
\text { activities - don't know } \\
\text { where to click to sign-up } \\
\text { and pay } \\
\text { \#Problem3 - Parents have } \\
\text { difficulty finding activities } \\
\text { close in proximity }\end{array}$ & $\begin{array}{l}\text { SOLUTION } \\
\text { \#Problem1 Solution - } \\
\text { Aggregate and filter } \\
\text { information on activities, } \\
\text { including location, user } \\
\text { reviews, activity } \\
\text { schedules, and price. } \\
\text { \#Problem2 Solution - } \\
\text { Register and pay directly } \\
\text { through the app, as well } \\
\text { as avoid multiple data } \\
\text { entry. } \\
\text { \#Problem3 Solution Geo- } \\
\text { mapping feature to list } \\
\text { activities based on } \\
\text { proximity }\end{array}$ & $\begin{array}{l}\text { UNIQUE VALUE } \\
\text { PROPOSITION } \\
\text { Saving you time for what is } \\
\text { really important, cause } \\
\text { finding extracurriculars is } \\
\text { not rocket science. }\end{array}$ & $\begin{array}{l}\text { UNFAIR ADVANTAGE } \\
\text { Database of Information } \\
\text { Faster process that allows } \\
\text { for one-click registration } \\
\text { and payment }\end{array}$ & $\begin{array}{l}\text { CUSTOMER } \\
\text { SEGMENTS } \\
\text { This would be a double } \\
\text { sided market } \\
\text { Front End Customers - } \\
\text { \#Parents of Children and } \\
\text { Youth aged 3-17 } \\
\text { Back End Customers - } \\
\text { \#Organizations that offer } \\
\text { programs/activities for } \\
\text { children aged 3-17 }\end{array}$ \\
\hline $\begin{array}{l}\text { COST STRUCTURE } \\
\text { Development - Fixed } \\
\text { Operating Costs (including S } \\
\text { Staffing - Fixed/Variable }\end{array}$ & rver Storage) - Fixed & & \multicolumn{2}{|c|}{$\begin{array}{l}\text { REVENUE STREAMS } \\
\text { Commission from every activity registered for - based on partnership } \\
\text { agreement with program/activity } \\
\text { Ad Placement on App } \\
\text { Data Entry fee charged to organizations partnered with }\end{array}$} \\
\hline
\end{tabular}

Lean Canvas is adapted from The Business Model Canvas (BusinessModelGeneration.com) and is licensed under the Creative Commons Attribution-Share Alike 3.0 Un-ported License. 


\section{Appendix C - Branding}

\section{Philosophy}

Launch Minds has a unique positioning as it focuses on parents as primary users, while reflecting a child environment seeing that it offers activities targeted at children and youth. Accordingly, the brand must reflect a playful yet simple and clean design that is easy to navigate. One of the key elements in the design of the brand and service, is developing a user-friendly interface that creates a rich experience.

\section{Typography}

When picking the fonts it was important to maintain the brand voice and aesthetic being professional yet playful. A combination of a serif and a sanserif font were used to portray the desired feel, as well as create contrast to differentiate the elements. In addition, the sans serif font used had different weight options to help further define the sub elements.

\section{Launch Minds}

This is a sample sentence.

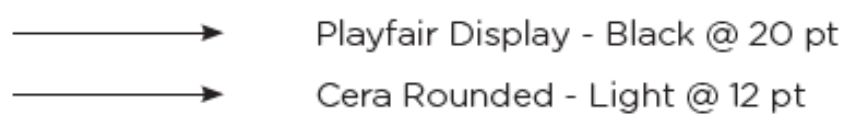

\section{Logo}

As the logo would be at the forefront of the brand it was important to conceptualize a design that was legible, adaptable, and a true representation of its voice. Accordingly, the Playfair display font was utilized as its clearly defined lines and serifs increased the legibility of the text creating a clean, simple, and professional design. In addition, the rocket which is an important element of the brand representing the "Launch" in the company name, was 
incorporated into the logo to add a visual element. The rocket also serves as a key design icon to be used as the favicon and within the app, creating an easily identifiable brand.

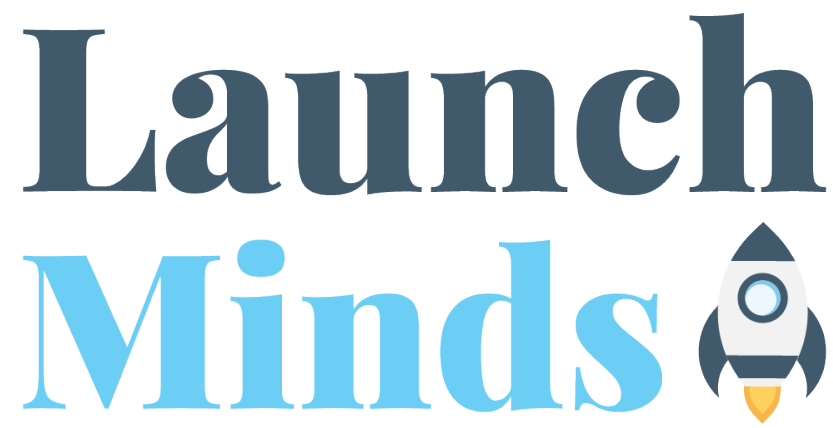

\section{Primary Colour Scheme}

As the logo would be at the forefront of the brand it was important to conceptualize a design that was legible, adaptable, and a true representation of its voice. Accordingly, the Playfair display font was utilized as its clearly defined lines and serifs increased the legibility of the text creating a clean, simple, and professional design. In addition, the rocket which is an important element of the brand representing the "Launch" in the company name, was incorporated into the logo to add a visual element. The rocket also serves as a key design icon to be used as the favicon and within the app, creating an easily identifiable brand.

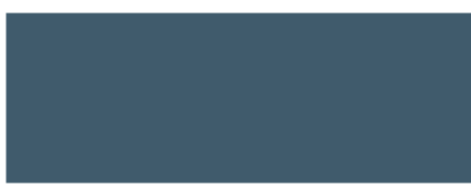

\begin{tabular}{lllll} 
HEX & 415 A6B & & & \\
RGB & 65 & 90 & 107 & \\
CMYK & 78 & 57 & 43 & 21 \\
& & & & \\
& \multicolumn{5}{c}{ 6CCEF4 } & & & \\
HEX & 61 & 206 & 244 & \\
RGB & 108 & 20 & 1 & 0 \\
CMYK & 51 & 0 & &
\end{tabular}




\section{Supplementary Colour Scheme}

Additional complimentary colours are used throughout the website and app design to create contrast to differentiate the different elements and help them stand out. For example, a relatively bright shade of red is used for decision buttons to ensure they are noticeable and encourage action.

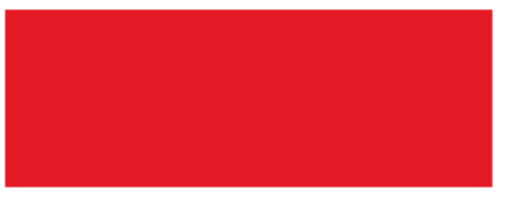

\begin{tabular}{lllll} 
HEX & \multicolumn{2}{l}{ E6OAOO } & & \\
RGB & 230 & 10 & 0 & \\
CMYK & 3 & 100 & 100 & 0
\end{tabular}

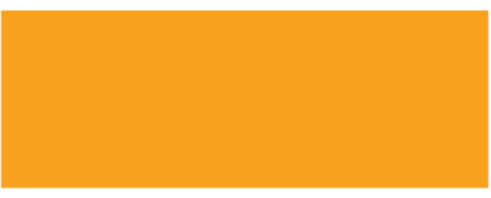

HEX

RGB

FDAIIA

CMYK

253

161

43

26

CMYK

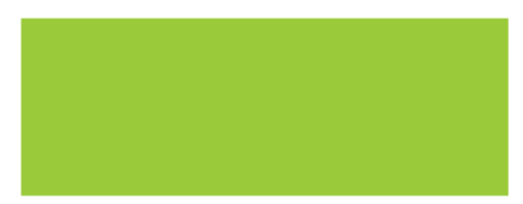

HEX

9DD12C

RGB 157

20944

CMYK 43

O 100

O 


\section{Appendix D - Design Iterations}

\section{First Prototype}
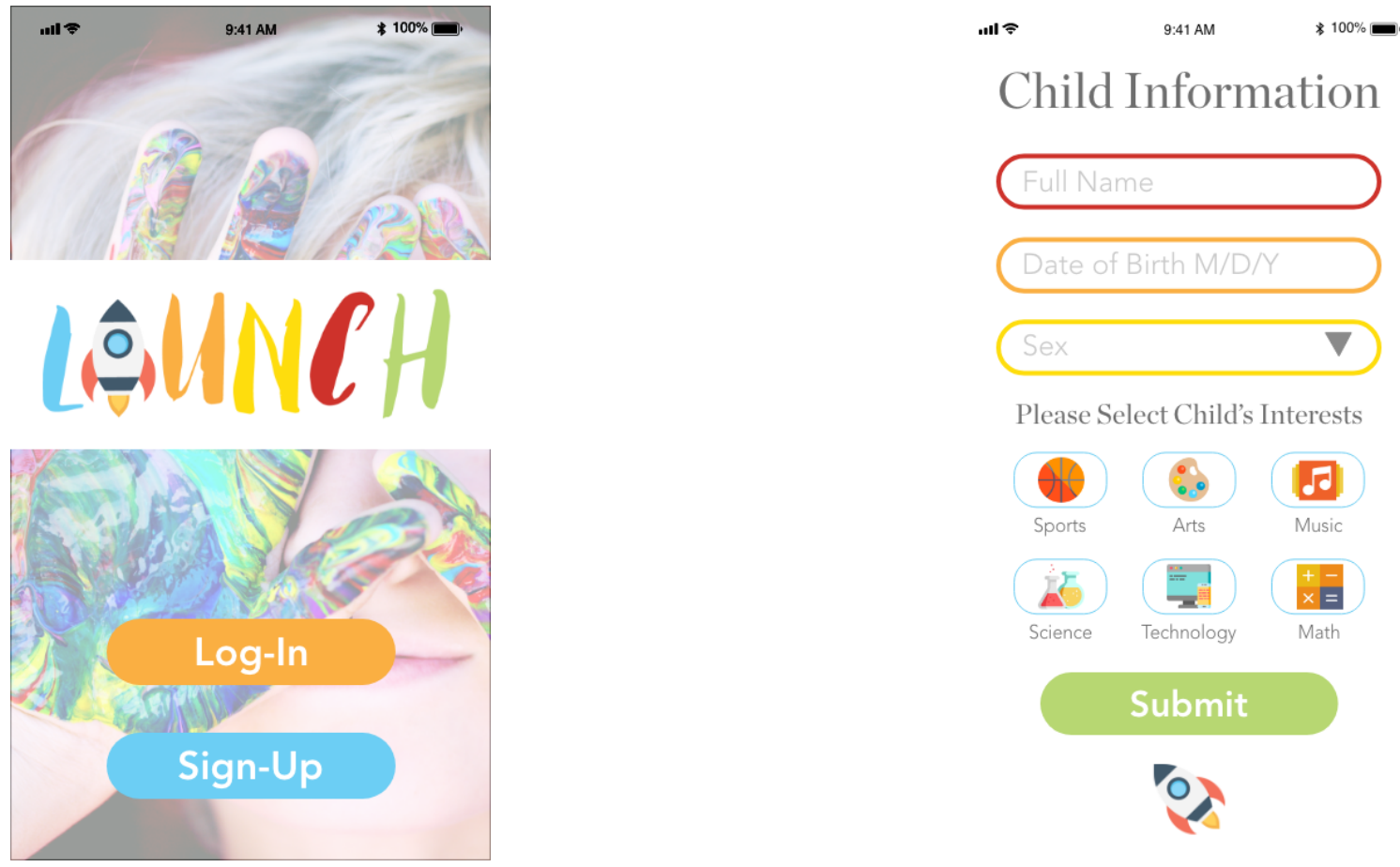

Please Select Child's Interests

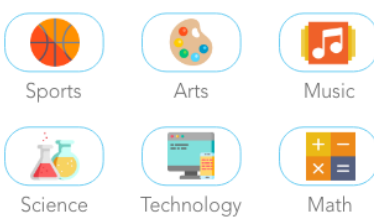

\section{Submit}
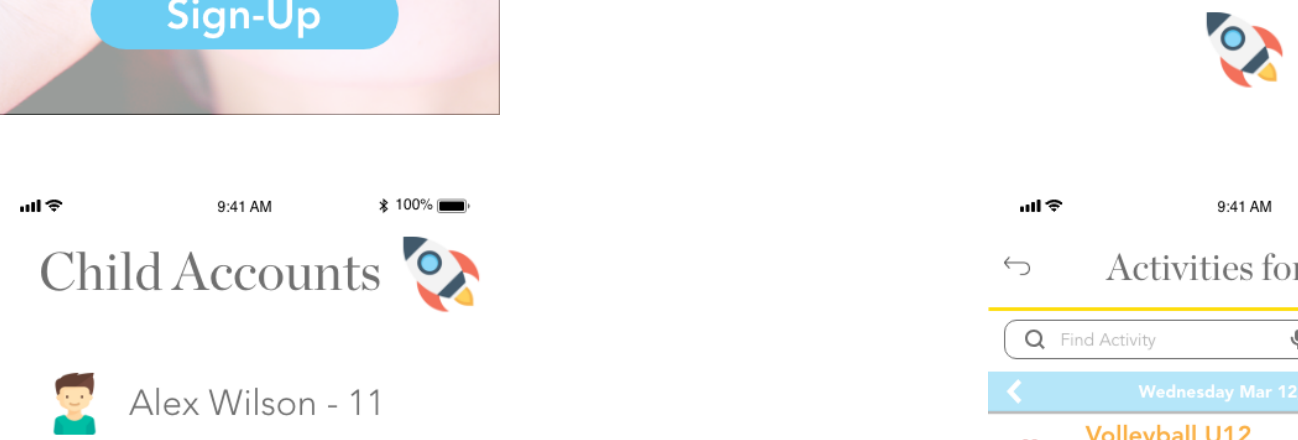

\section{Current Activities}

Find Activities

\section{Edit Account}

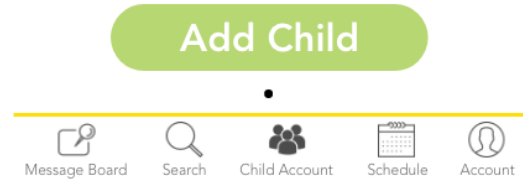




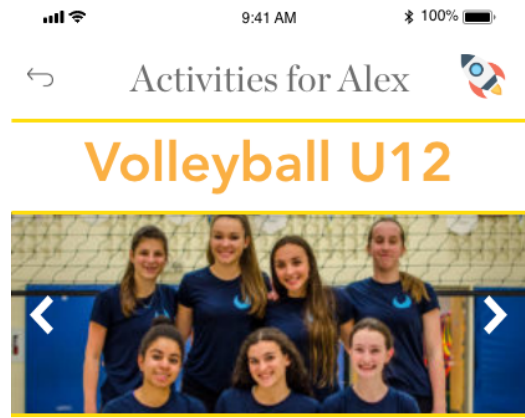

13-Week Program $\bigcirc$

The Academy program challenges players to quickly acquire the physical, technical, and tactical fundamental skills to be more proficien
at volleyball gameplay aspiring to make a competitive rep OVA team or school volleyball tearm.

\section{Register}

\begin{tabular}{ll}
\hline Price & Schedule \\
$\$ 410$ & Wednesdays, 7:00 pm-8:30 pm \\
\hline
\end{tabular}

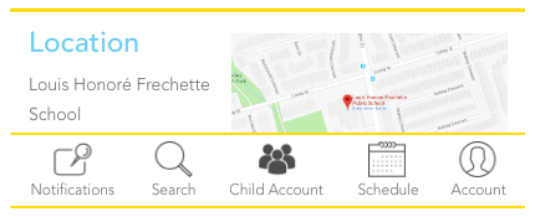

About the Organizer

Unity Volleyball

Phone: +1 4169856959

Email: admin@unitysports.ca

\section{UUNITY}

Web: www.unityvolleyball.ca

User Reviews th 40

John Doe - 4.5/5.

"My children really enjoy attending the practice, the coaches are very engaging, and help them learn through games."

Michelle Clark - 3.5/5.0

"My children look forward to practice every week. However, I

wish there was a better way to advance children with a similar

skill level."

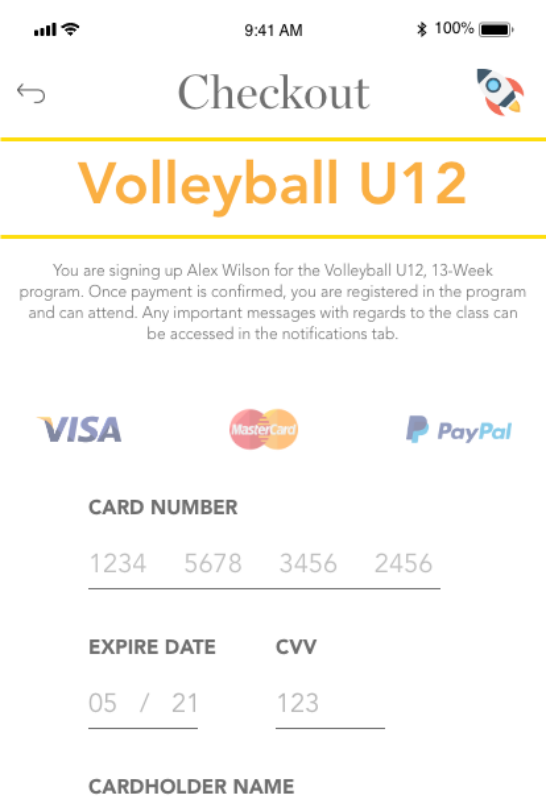

John Doe

$\underset{\text { Notifications }}{8} \underbrace{83}_{\text {Search }}$

Pay Secure 


\section{Second Prototype}
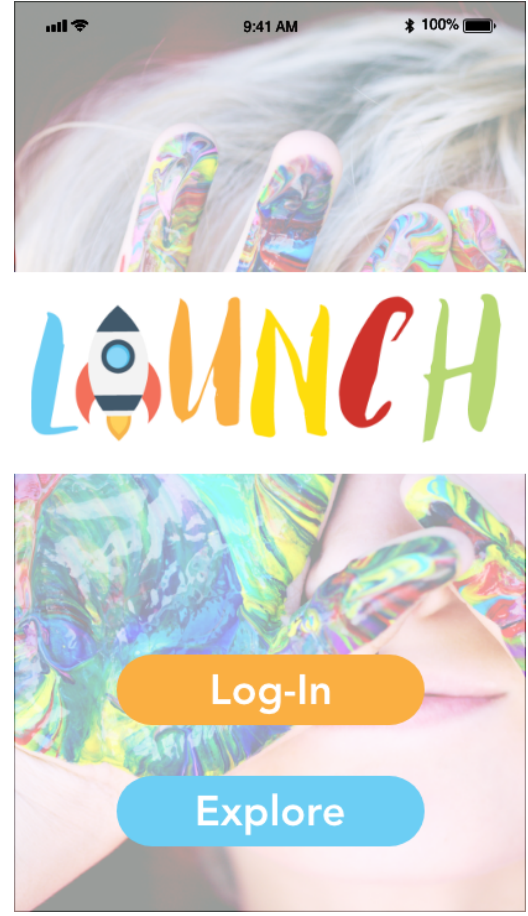

.แ1

9:41 AM

Child Information

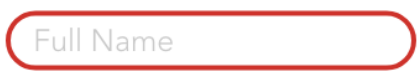

Date of Birth M/D/Y

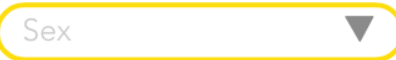

Please Select Child's Interests

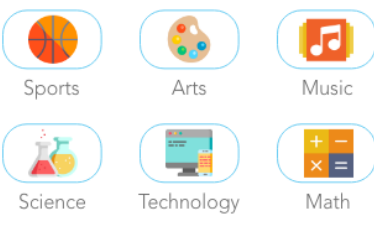

Submit

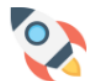

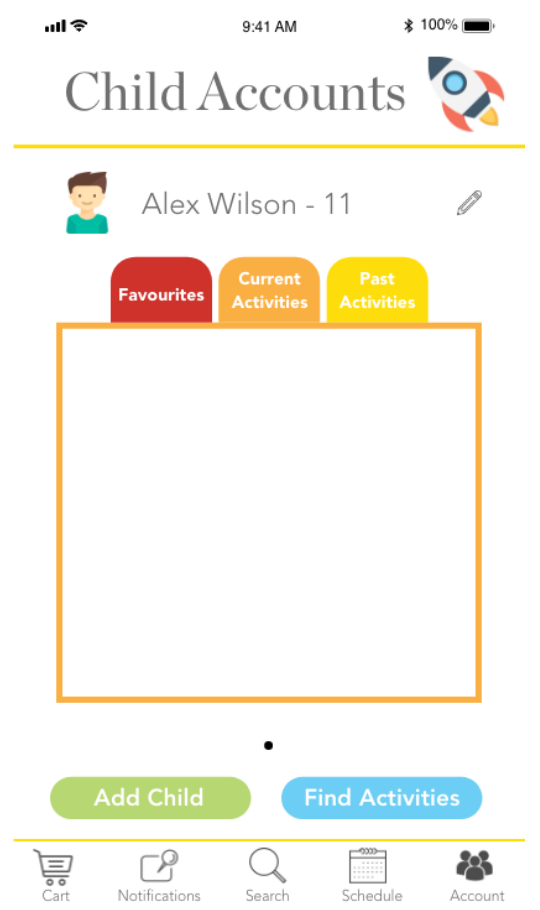

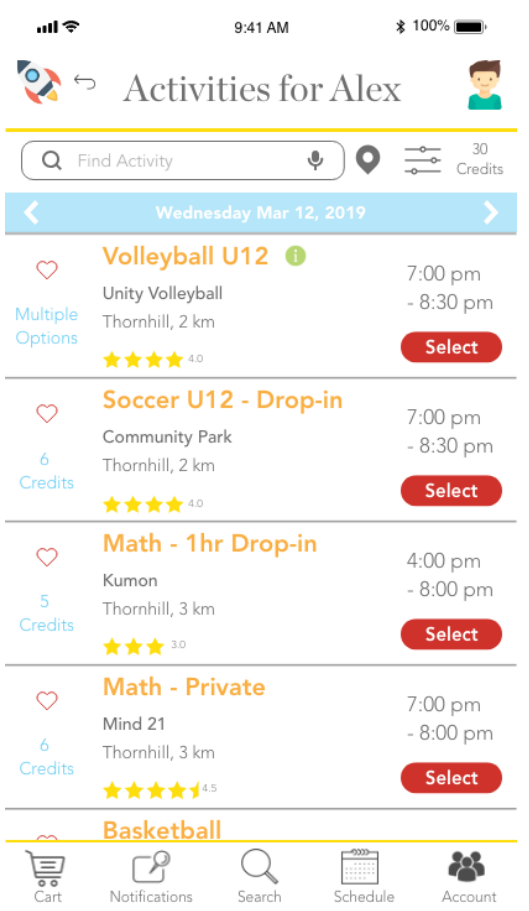




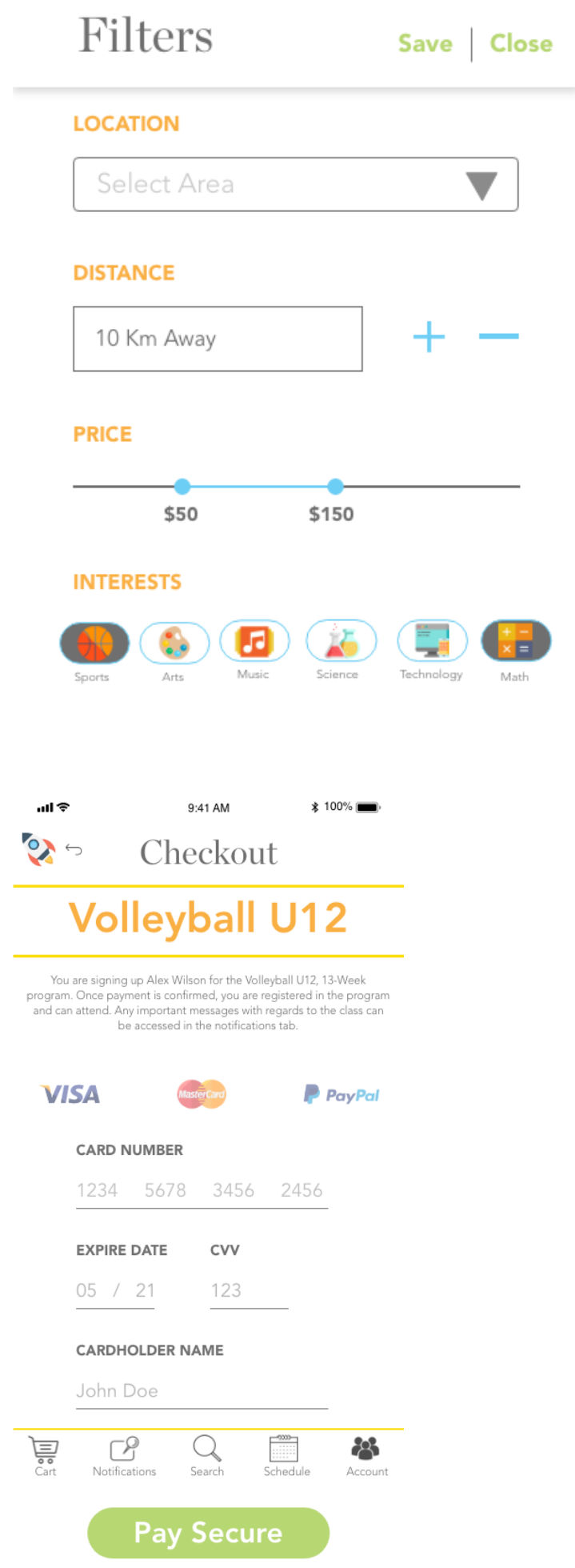

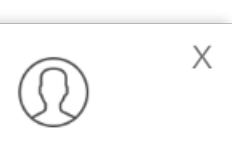

Sandy Soccer Mom

Edit Account
$\theta$ Billing Information
if Invite Friends
? Get Help
$\square$ Give Us Feedback

Children Accounts

2. Alex

B Summer

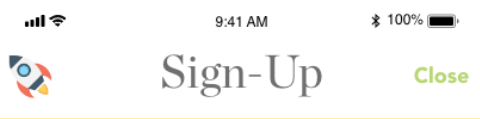 \\ Join the Launch Community \& Discover Your Child's Next Activity!}

\section{f Facebook G Google}

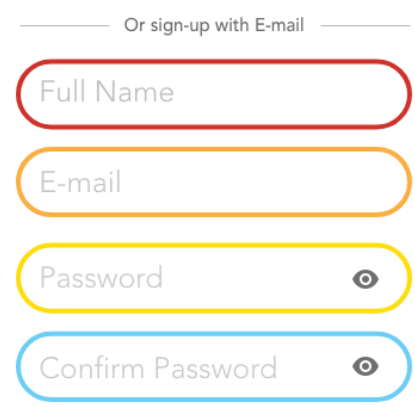

Subscribe to receive our newsletter, resources, and updates!

Opt-in

\section{Submit}




\section{Final Prototype}

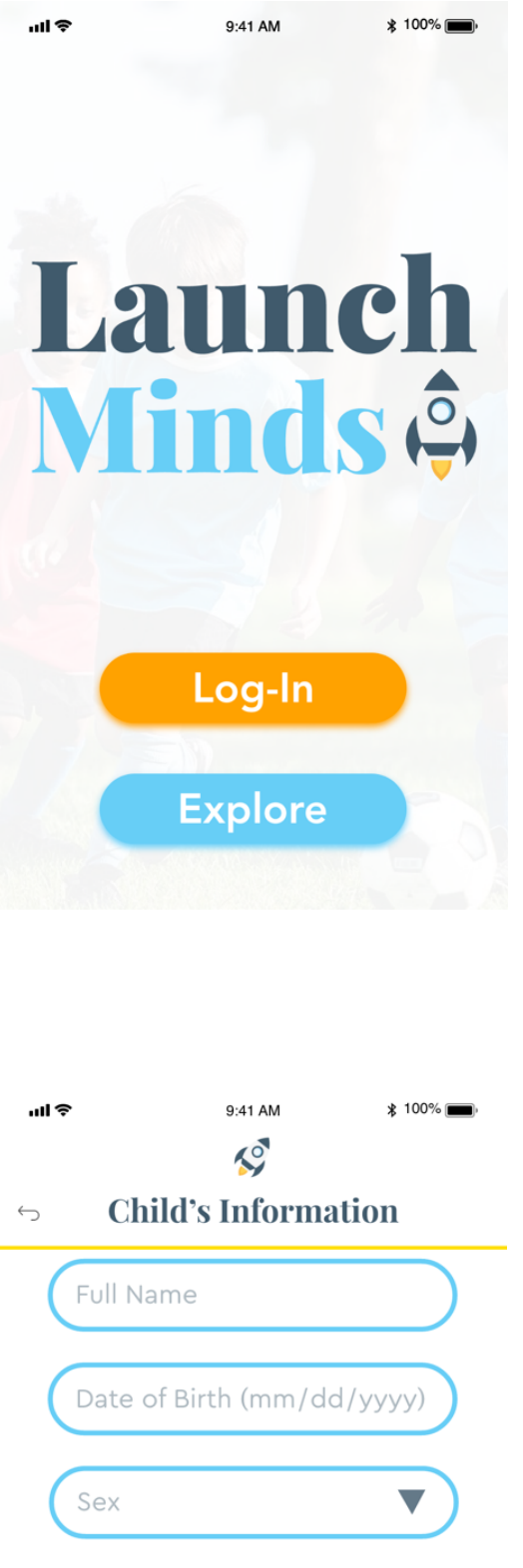

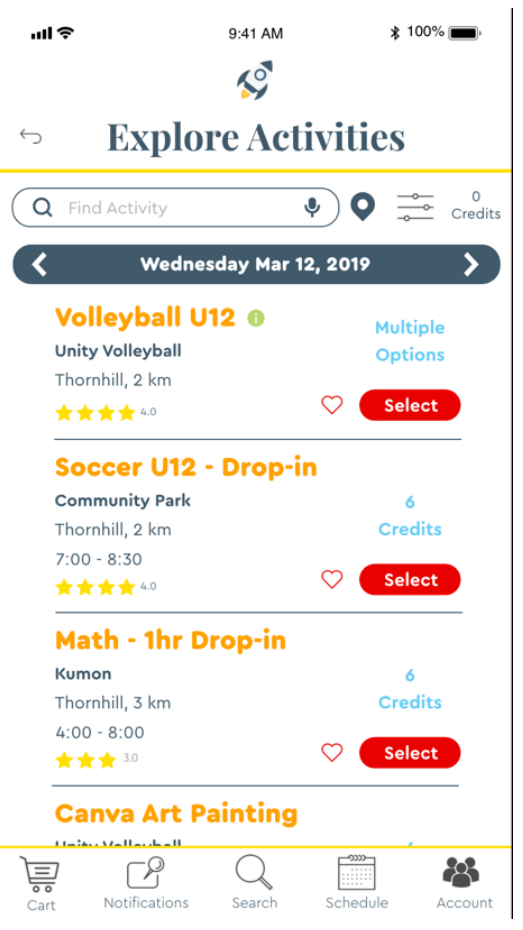
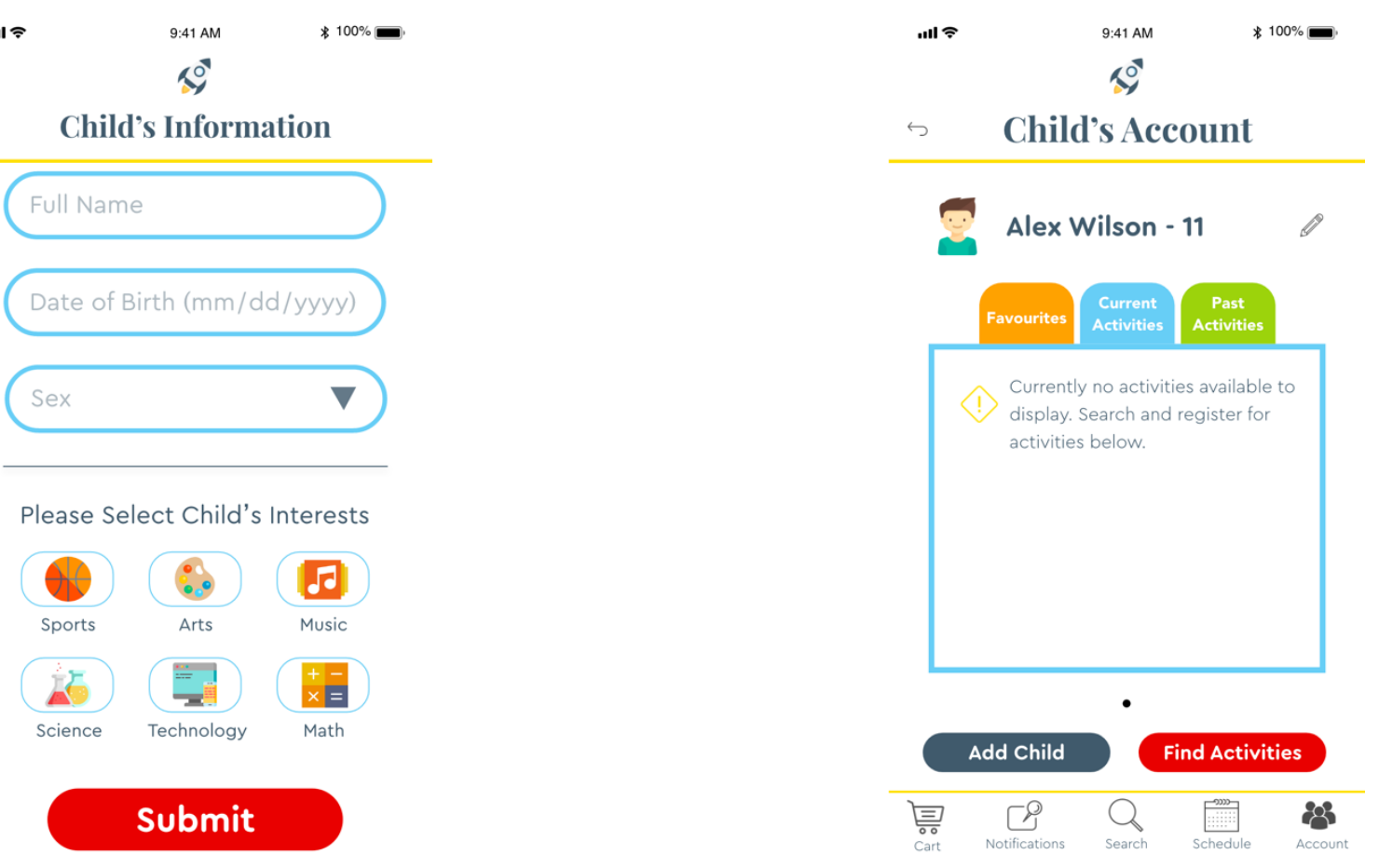

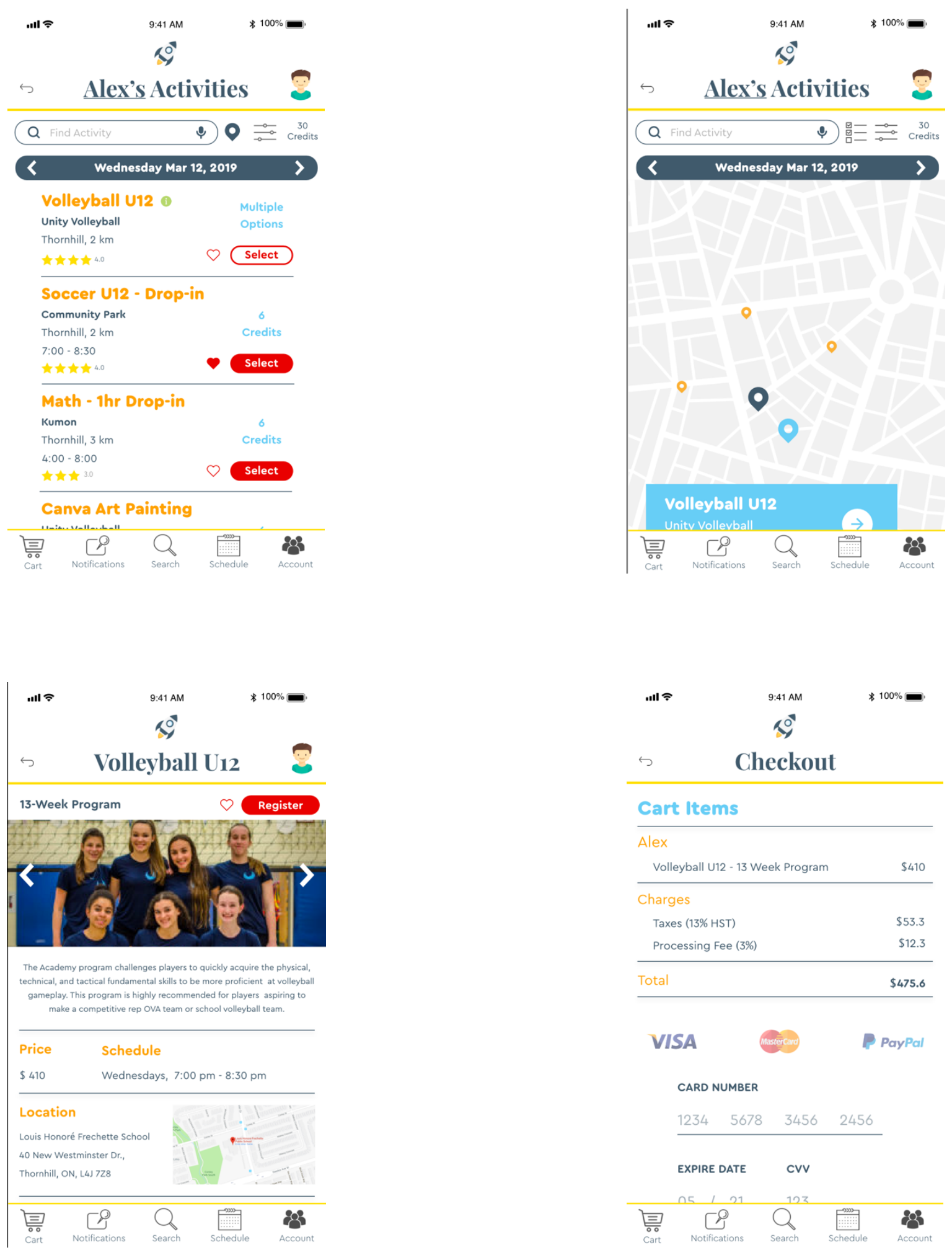

\begin{tabular}{|c|c|}
\hline \multicolumn{2}{|l|}{ Alex } \\
\hline Volleyball U12 - 13 Week Program & $\$ 410$ \\
\hline \multicolumn{2}{|l|}{ Charges } \\
\hline Taxes (13\% HST) & $\$ 53.3$ \\
\hline Processing Fee (3\%) & $\$ 12.3$ \\
\hline Total & $\$ 475.6$ \\
\hline
\end{tabular}

\begin{tabular}{|c|c|c|c|c|}
\hline VISA & \multicolumn{2}{|c|}{ Atasereng } & & PayPal \\
\hline \multicolumn{5}{|c|}{ CARD NUMBER } \\
\hline 1234 & 5678 & 3456 & 2456 & \\
\hline \multicolumn{2}{|c|}{ EXPIRE DATE } & cvV & & \\
\hline \multicolumn{2}{|c|}{$\equiv \quad \rho^{01}$} & $12 z$ & & \\
\hline $\begin{array}{l}\text { Dotif } \\
\text { Cart } \\
\text { Cat }\end{array}$ & tions & earch & Schedule & 8 \\
\hline
\end{tabular}


..I 준

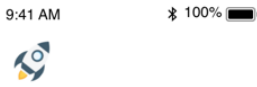

$\hookleftarrow \quad$ Payment Confirmation

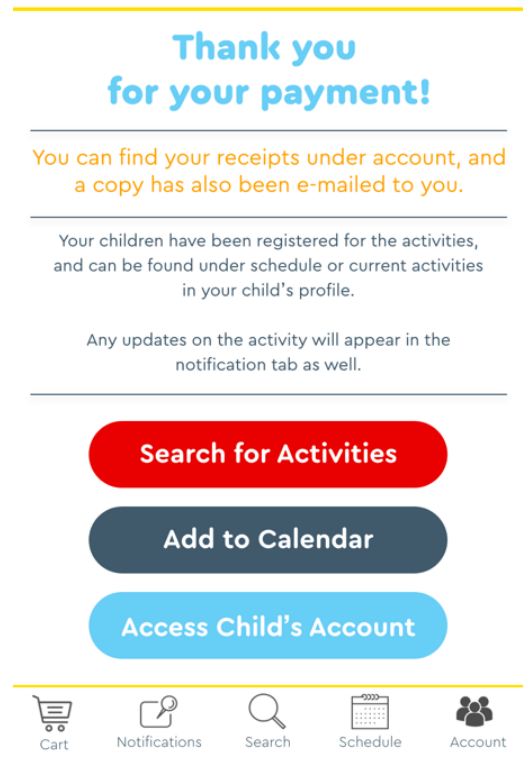

.แ1 จ

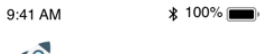

(8)

\section{Schedule}

= March 2019

Q | Sync

March 2019

$01 \quad 02$

$\begin{array}{lllllll}03 & 04 & 05 & 06 & 07 & 08 & 09\end{array}$

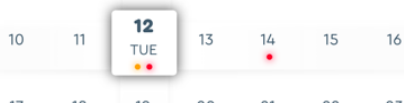

$\begin{array}{lllllll}17 & 18 & 19 & 20 & 21 & 22 & 23\end{array}$

$\begin{array}{lllllll}24 & 25 & 26 & 27 & 28 & 29 & 30\end{array}$

$\begin{array}{lllllll} & & \bullet & & & 29 & 30 \\ M & \text { T } & \text { W } & \text { T } & \text { F } & \text { S } & \text { S }\end{array}$

Wednesday March 12, $2019 \quad$ \#

- Volleyball U12 - Alex

Unity Volleyball

- Canva Art Painting

Dura Art Centre

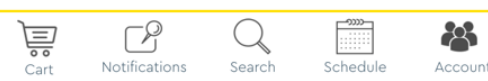




\section{References}

(2017, August 3). 2016 Census: Families, households and marital status; Language . Retrieved from https://www.toronto.ca/wp-content/uploads/2017/10/96e4-2016-CensusBackgrounder-Family-Households-Languages.pdf

(2018, July 11). Back To School: Investing In Kids' Extracurricular Activities. Retrieved from https://www.forbes.com/sites/capitalone/2018/07/11/back-to-school-investing-in-kidsextracurricular-activities/

Curtis, S. (2017, May 31). Toddlers at risk of tech addiction as parents rely on gadgets to entertain kids. Retrieved from https://www.mirror.co.uk/tech/toddlers-risk-developingtechaddiction-10530433

Dam, R., \& Siang, T. (2018). 5 Stages in the Design Thinking Process. Retrieved from https://www.interaction-design.org/literature/article/5-stages-in-the-designthinkingprocess

Eime, R. M., Young, J. A., Harvey, J. T., Charity, M. J., \& Payne, W. R. (2013). A systematic review of the psychological and social benefits of participation in sport for children and adolescents: Informing development of a conceptual model of health through sport. International Journal of Behavioral Nutrition and Physical Activity, 10(1), 98. doi:10.1186/1479-5868-10-98

Felfe, C., Lechner, M., \& Steinmayr, A. (2016). Sports and Child Development. PLOS ONE, 11(5), e0151729. doi: 10.1371/journal.pone.0151729

Guèvremont, A., Findlay, L. C., \& Kohen, D. E. (2011). Do high levels of extracurricular activities help or hinder child development?Canadian Council on Learning = Conseil canadien sur l'apprentissage.

Jamil, F. M., Linder, S. M., \& Stegelin, D. A. (2017). Early Childhood Teacher Beliefs About STEAM Education After a Professional Development Conference. Early Childhood Education Journal,46(4), 409-417. doi:10.1007/s10643-017-0875-5 
Kumar, P. (2018, February 1). The Growing Need of Experiential Marketing in New Age Marketing Mix. Retrieved from https://www.entrepreneur.com/article/308379

Mahoney J. L., \& Cairns, R. B. (1997). Do extracurricular activities protect against early school dropout? Developmental Psychology, 33, 241-253.

Mahoney, J. L., Larson, R., \& Eccles, J. S. (2008). Organized activities as contexts of development: Extracurricular activities, after-school, and community programs. New York: Psychology Press.

Olenski, S. (2018, August 17). 3 Reasons Why CMOs Should Embrace Experiential Marketing. Retrieved from https://www.forbes.com/sites/steveolenski/2018/08/15/3-reasons-whycmos-should-embrace-experiential-marketing/\#713998b37da6

Praise, encouragement and rewards. (2018). Retrieved from https://raisingchildren.net.au/toddlers/connecting-communicating/connecting/praise

Simpson, S. (2018, September 4). One in Three (32\%) Families Going into Debt to Fund their Children's Extra-Curricular Activities, Up 5 Points from Last Year. Retrieved from https://www.ipsos.com/en-ca/news-polls/back-to-school-2018 